\title{
HYPERBARIC OXYGEN THERAPY VERSUS LASER THERAPY ON THE ACCELERATION OF VENOUS LEG ULCER HEALING
}

\author{
Emad T.Ahmad, PT.D* \\ Faculty of Physical Therapy, Cairo University, Egypt
}

\begin{abstract}
The purpose of the current study was to determine the effectiveness of hyperbaric oxygen therapy(HBOT) or laser therapy in the acceleration of chronic venous ulcer healing. Thirty hospital inpatients with venous ulcers participated in this study for a treatment period of five weeks. They were divided randomly and equally into three groups ( 2 treatment groups and one control group). Patients in group (1) (HBOT group) received two 90 minutes treatments daily with 2 to3 L of humidified oxygen / minute at $22 \mathrm{mmHg}$. On the other hand, patients in group (2) (laser therapy group) received $1 \mathrm{~J} / \mathrm{cm}^{2}$ infrared laser ( $\mathrm{Ga} \mathrm{As}$ ), three times weekly. Patients in group (3) (control group) received standard wound care only. Wound surface area (WSA) and wound volume (WV) were used to measure the outcomes before starting the study and after the $3^{\text {rd }}$ and $5^{\text {th }}$ weeks posttreatment. It was found that, at the $5^{\text {th }}$ week post-treatment there was a significant reduction in both WSA and WV in both the HBOT group and the laser therapy group when compared to the control group $(\mathrm{P}<0.0001)$, also there was a significant reduction in WSA and WV in the laser therapy group at the $5^{\text {th }}$ week post-treatment when compared to the HBOT group $(\mathrm{P}<0.001)$. The findings strongly suggest that the application of infrared laser therapy at a dose of $1 \mathrm{~J} / \mathrm{cm}^{2}$, three times/week is more effective than the application of HBOT daily in the management of chronic venous ulcers.
\end{abstract}

\section{Introduction:}

Venous leg ulcers represent a significant medical, economic and social problem ${ }^{(2)}$. Many ulcers are chronic, having demonstrated poor responses to the conventional therapeutic approaches usually used for this entitiy. Baker and Stacey(3) reported that ulcers persisting for more than one year are a chronic problem for $24 \%$ of patients. Thirty-five percent of patients had had an ulceration problem for more than five years and $20 \%$ had suffered 10 or more episodes of ulceration.

\section{Oxygen and Wound Healing}

Falcone and Caldwell ${ }^{(7)}$ found that the metabolism of the cellular infiltrate directed the biochemical events of wound healing. The function of macrophages, fibroblasts, and endothelial cells is impaired if local perfusion and oxygenation are limited ${ }^{(10)}$. Collagen deposition is

\section{Addressee for Correspondence:}

Emad Tawfic Ahmed MD

Address: Health Science College for Male

At Taif Box: 2425

TEL : 00966027310607

MOBIL: 009660501608604

Email: Emadtawfik72@yahoo.com directly related to oxygen tension; at oxygen levels of less than $20 \mathrm{~mm} \mathrm{Hg}$, collagen synthesis is severely retarded or ceases completely. Also, perfusion is critical for granulocytes to ingest bacteria and foreign bodies, and insufficient oxygen may lead to an increased bacterial load $(9)$

Hypoxia (decreased tissue oxygen) in the wound space is a stimulus to angiogenesis, but collagen production in mature fibroblasts requires oxygen. Thus, hypoxia results in a delay in healing. Alternatively, hyperoxia results in faster healing Angiogenesis is accelerated when oxygen in the circulation is increased. ${ }^{(10)}$

Hunt and Pai ${ }^{(10)}$ showed that the rate of synthesis of collagen in closed wounds is accelerated in hyperoxia. Pai and Hunt ${ }^{(15)}$ also found that hyperoxia accelerated healing and epithelialization in open wounds in rats. Other researchers have found hyperbaric oxygen accelerated healing in devascularized wounds ${ }^{(12)}$

The premise for the use of hyperbaric oxygen is

Manuscript received: May 2008

Accepted for publication: May 2008 
that increased tissue oxygen tension in the wound improves and accelerates resistance to bacteria, collagen synthesis, angiogenesis, and epithelialization. Several investigators have shown that hyperbaric oxygen improved healing in chronic wounds ${ }^{(9)}$

\section{Laser and wound healing:}

The use of laser as a non-surgical medical treatment modality for assisting the normal processes of healing has increased over the last few years. However, the efficacy of laser in reducing pain or promoting tissue repair still remains controversial ${ }^{(6)}$. Laser therapy aims at restoring the normal biological function of injured or stressed cells so 'Normalization' is the keystone of laser therapy ${ }^{(22)}$. In the clinical setting, low intensity laser therapy has been reported as effective in the treatment of chronic venous ulceration(21), soft tissue lesions, and for the stimulation of healing in both acute and chronic wounds ${ }^{(13)}$

The majority of authors have reported that lasermodulated wound healing most often occurs during the proliferative phase $(5,23)$. It is thought that such effects occur due to the enhancement of cell metabolic processes as a result of laser therapy, therapy affecting the electrophysiological properties of the tissue ${ }^{(17)}$ Laser irradiation has been shown to affect most of the cell types involved in wound healing: in two recent studies, laser irradiation was reported to activate fibroblasts $^{(1)}$. Young and Dyson ${ }^{(23)}$ also reported that laser therapy stimulated macrophages, and therefore, is effective during the inflammatory stage of repair, and the authors also previously concluded that laser irradiation stimulates macrophages to release chemical mediators, cytokines, and growth factors, which in turn activate the later stages of wound repair ${ }^{(23)}$.

Pereira et al(16) studied the effect of a $120 \mathrm{~mW}$ GaAs diode laser on fibroblasts and concluded that 3 $\mathrm{J} / \mathrm{cm}^{2}$ stimulated fibroblast proliferation without impairing procollagen synthesis.
The purposes of the study were:

1- To determine a HBOT treatment protocol.

2- To determine if either HBOT or laser therapy would be more effective in accelerating venous ulcer healing

\section{Subjects and methods:}

\section{Subjects.}

Thirty hospital inpatients with chronic open wounds due to chronic venous insufficiency participated in this study. The inclusion criteria: We considered venous insufficiency to be present if a subject had varicosities, gravity-dependent leg edema, lipodermatosclerosis, or hemosiderin staining of the lower extremity ${ }^{(11)}$. The exclusion criteria: diabetes, arteriosclerosis, rheumatoid arthritis, or any other entity known to interfere with the healing process. Persons were also excluded from the study if they were undergoing corticosteroid therapy. Other exclusion criteria included any of the following medical conditions for which hyperbaric oxygen therapy is contraindicated: pneumothorax, chronic obstructive pulmonary disease, pneumonia, seizure, upper respiratory tract infection, pregnancy, and heart diseases. Thirty patients were recruited into the study, and were randomly and equally divided into three comparative groups A, B and C. Subjects selected for the study gave informed consent and were assigned an ID code to ensure confidentiality.

Group A consisted of 10 patients (6 females, 4 males). The patients in this group were treated with the hyperbaric oxygen therapy in addition to standard wound care. Group B consisted of 10 patients (5 females, 5 males). They were treated with infra-red laser therapy in addition to standard wound care. Group C consisted of 10 patients ( 3 females, 7 males). The patients in this group received standard wound care only consisting of wound cleansing twice daily using hydrogel to keep the wound moist. All wounds were debrided before admission to the study. Table 1 provides a general description of the study population

Table 1: General characteristics of HBOT, Laser and control groups

\begin{tabular}{ccccc}
\hline Statistical group & Sex $(\mathbf{M} / \mathbf{F})$ & Age $(\mathbf{y r})^{*}$ & Wound duration (months)* & Location Toe/foot/ankle/leg \\
\hline HBOT group & $4 / 6$ & $55.60 \pm 3.95$ & $5.40 \pm 0.39$ & $1 / 2 / 6 / 1$ \\
\hline Laser group & $5 / 5$ & $56.20 \pm 3.94$ & $5.45 \pm 0.49$ & $1 / 3 / 5 / 1$ \\
\hline Control group & $7 / 3$ & $55.20 \pm 3.91$ & $5.50 \pm 0.47$ & $2 / 2 / 5 / 1$ \\
\hline
\end{tabular}

* Mean \pm S.D. 
for the study and control groups.

In order to rule out the arterial component and for localization of chronic venous insufficiency, patients were examined with Doppler-duplex ultrasound using 7.5 MHz and 2.5 MHz probes (EUB 555, Hitachi, Japan).

\section{Equipments:}

- Hyperbaric oxygen therapy: this was performed with a Schrist 3300 E mono-place chamber ( Schrist company): Sechrist's Oxygen Conservation System provides the following benefits:

1. Using the O2 Conservation Mode, up to $65 \%$ less oxygen will be consumed per treatment compared to standard pneumatic chambers

2. Reduced oxygen supply requirements

3. $95 \%$ oxygen level within 10 minutes in the chamber at a minimum compression purge rate of $400 \mathrm{~L} / \mathrm{min}$

4. Greatly reduced noise levels during the pressure plateau

Maximum Operating Pressure: 3.04 atmospheres absolute [ATA]).

- Laser therapy: This was performed with an IR-27 laser therapy system ( Electronica Pagani S.r.l., Italy) which is a GaAs laser source ( wave length: $904 \mathrm{~nm}$, frequency:5-7000 Hz, average output power: $17 \mathrm{mw}$ )

\section{Procedure of the study:}

Treatment procedure: Both treatments were administered by a licensed physical therapist.

- Hyperbaric oxygen therapy group: The hyperbaric oxygen therapy was applied daily at morning using the Schrist $3300 \mathrm{E}$ chamber as described above. Patients received two 90-minute treatments daily with $2 \mathrm{~L}$ to $3 \mathrm{~L} / \mathrm{min}$ of humidified oxygen delivered at $22 \mathrm{~mm} \mathrm{Hg}$.

- Laser therapy group: This group received infrared laser (GaAs diode system) three times weekly. The probe was covered with shrink-wrap plastic to prevent contamination of wounds, and treatment was given in contact, with the probe centered over the ulcer. For small wounds, the probe spanned the ulcer and surrounding skin, and one exposure comprised the whole treatment at $1 \mathrm{~J} / \mathrm{cm}^{2}$. For larger wounds, in addition to the central application, the probe was advanced around the wound perimeter until the entire perimeter had been exposed to laser irradiation at $1 \mathrm{~J} / \mathrm{cm}^{2}$ per spot.

- Control group: This group received standard wound care only, consisting of wound cleansing twice daily using Hygeol (Warnpole Inc, Penh, Ontario, Canada K7H 3E6.) (1:20), ( One part 1\% chlorine solution diluted in 19 parts water) (Smith \& Nephew Medical Ltd, Hull, England HU3 2BN) to keep the wound surface moist.

\section{Assessment procedure:}

\section{1- Wound surface area (WSA) measurement:}

The WSA measurement was conducted by tracings of the wound perimeters as reported by Kloth and Feedar ${ }^{(14)}$. The wound surface area measurement was conducted as follows a sterilized transparency film was placed over the ulcer. The ulcer's perimeter was traced with a fine-tipped transparency marker. Each ulcer was traced 3 times to establish measurement reliability. After tracing, the surface of the transparency film which had been in contact with the ulcer was cleaned with cotton and alcohol. Carbon paper was placed over $1 \mathrm{~mm}^{2}$ metric graph paper. The transparency film with the tracing was placed, traced surface uppermost, over the carbon paper with sheet of white paper in between them, and the tracing was transcribed onto the metric graph paper. The number of square millimeters on the metric graph within the wound tracing were counted to determine the WSA. The mean of the 3 trials was calculated and considered as the WSA. The WSA measurements were taken at zero (pre), and the $3^{\text {rd }}$ (post I) and $5^{\text {th }}$ ( post II) weeks post-treatment.

\section{2- Wound volume measurement:}

Saline has been used to measure wound volume for many years. Berg et $\mathrm{al}^{(4)}$. described this straightforward approach: the wound is covered with a transparent, elastic and adhesive thin layer of plastic material similar to semi-permeable film dressing. The cavity between the wound and the transparent film can then be filled by injecting saline solution with a calibrated syringe through the film. The amount of saline that is necessary to fill the wound is a direct measure of the wound volume. The accuracy of the method is influenced by the capability of the physician or nurse to accurately inject exactly that amount of saline into the cavity that is necessary for the adhesive film to follow the former original surface of the skin. In the present study, wound volume (WV) measurements were taken at zero (pre), and the $3^{\text {rd }}$ (post I) and $5^{\text {th }}$ (post II) posttreatment weeks.

Data analysis. A paired Student's $t$-Test was conducted 
to compare both the wound area and volume at baseline and after the $3^{\text {rd }}$ and $5^{\text {th }}$ weeks post-treatment. An unpaired Student's t-test was conducted to compare both treatment groups (HBOT, Laser) with the control group.

\section{Results:}

\section{Results of the HBOT group:}

As shown in Table 2 the mean value and standard deviation of the WSA in $\mathrm{cm}^{2}$ ) in this group before application of the treatment was $3.95 \pm 0.17 \mathrm{~cm}^{2}$, while the mean values of the WSA after application of HBOT measured after the third and fifth weeks were $3.04 \pm 0.08$ and $2.27 \pm 0.21 \mathrm{~cm}^{2}$, respectively. On the other hand, the mean value and standard deviation of wound volume (WV, $\mathrm{ml}$ ), in this group before application of the treatment was $2.96 \mathrm{ml}$, while the mean values of the WV after application of HBOT measured after the third and fifth weeks were $2.08 \pm 0.11$ and $1.54 \pm 0.16 \mathrm{ml}$, respectively.

As observed from Table 2 there was a significant decrease in both the WSA and WV measured after the third and fifth weeks post application of HBOT compared to initial measurement at baseline $(\mathrm{P}<0.0001)$.

\section{Results of the laser group:}

As shown in Table 3 the mean value and standard deviation of the WSA in $\mathrm{cm}^{2}$ in this group before application of the treatment was $4.01 \mathrm{~cm}^{2}$, and the mean WSA values after application of laser therapy measured after the third and fifth weeks were $3.02 \pm 0.13$ and $1.92 \pm 0.20 \mathrm{~cm} 2$, respectively. On the other hand, the mean value and standard deviation of he $\mathrm{WV}$ in $\mathrm{ml}$ in this group before application of the treatment was $3.0 \pm 0.14 \mathrm{ml}$, while the mean $\mathrm{WV}$ values after application of laser therapy measured after the third and fifth weeks were $2.06 \pm 0.11$ and $1.3 \pm 0.14 \mathrm{ml}$, respectively.

As observed from Table 3 there was a significant decrease in both the WSA and WV measured after the third and fifth weeks post application of laser compared to the baseline values $\mathrm{P}<0.0001$ ).

\section{Results of the control group:}

As shown in Table 4 the mean value and standard deviation of the WSA in $\mathrm{cm} 2$ in this group before

Table 2: The statistical analysis of the differences of wound area and volume in the HBOT group pre \& post treatment ( third and fifth weeks)

\begin{tabular}{|c|c|c|c|c|c|c|c|c|}
\hline \multirow[t]{2}{*}{ Stat. group } & \multicolumn{4}{|c|}{ Wound surface area (WSA) $\left(\mathrm{Cm}^{2}\right)$ HBOT group } & \multicolumn{4}{|c|}{ Wound Volume (WV) (ml) HBOT group } \\
\hline & $\begin{array}{c}\text { Initial Area } \\
\text { (pre) }\end{array}$ & $\begin{array}{l}3^{\text {rd }} \text { week } \\
\text { Post-tre }\end{array}$ & $\begin{array}{c}\text { Initial area } \\
\text { (pre) }\end{array}$ & $\begin{array}{l}5^{\text {th }} \text { week } \\
\text { Post-tre }\end{array}$ & $\begin{array}{l}\text { Initial Volume } \\
\text { (pre) }\end{array}$ & $\begin{array}{l}3^{\text {rd }} \text { week } \\
\text { Post-tre }\end{array}$ & $\begin{array}{c}\text { Initial volume } \\
\text { (pre) }\end{array}$ & $\begin{array}{l}5^{\text {th }} \text { week } \\
\text { Post-tre }\end{array}$ \\
\hline Mean & 3.95 & 3.04 & 3.95 & 2.27 & 2.96 & 2.08 & 2.96 & 1.54 \\
\hline S.D.土 & 0.17 & 0.08 & 0.17 & 0.21 & 0.19 & 0.11 & 0.19 & 0.16 \\
\hline S.E. & 0.05 & 0.02 & 0.05 & 0.06 & 0.06 & 0.03 & 0.06 & 0.05 \\
\hline t.value & \multicolumn{2}{|c|}{16.65} & \multicolumn{2}{|c|}{19.98} & \multicolumn{2}{|c|}{22.64} & \multicolumn{2}{|c|}{22.58} \\
\hline P.value & \multicolumn{2}{|c|}{0.0001} & \multicolumn{2}{|c|}{0.0001} & \multicolumn{2}{|c|}{0.0001} & \multicolumn{2}{|c|}{0.0001} \\
\hline Level of sig. & \multicolumn{2}{|c|}{$S$} & \multicolumn{2}{|c|}{$S$} & \multicolumn{2}{|c|}{$S$} & \multicolumn{2}{|c|}{ S } \\
\hline
\end{tabular}

Table 3: The statistical analysis of the differences of wound area and volume in the Laser group pre \& post treatment ( third and fifth weeks).

\begin{tabular}{|c|c|c|c|c|c|c|c|c|}
\hline \multirow[t]{2}{*}{ Stat. group } & \multicolumn{4}{|c|}{ Wound surface area (WSA) $\left(\mathrm{Cm}^{2}\right)$ Laser group } & \multicolumn{4}{|c|}{ Wound Volume (WV) (ml) Laser group } \\
\hline & $\begin{array}{c}\text { Initial Area } \\
\text { (pre) }\end{array}$ & $\begin{array}{l}3^{\text {rd }} \text { week } \\
\text { Post-tre }\end{array}$ & $\begin{array}{c}\text { Initial area } \\
\text { (pre) }\end{array}$ & $\begin{array}{l}5^{\text {th }} \text { week } \\
\text { Post-tre }\end{array}$ & $\begin{array}{l}\text { Initial Volume } \\
\text { (pre) }\end{array}$ & $\begin{array}{l}3^{\text {rd }} \text { week } \\
\text { Post-tre }\end{array}$ & $\begin{array}{c}\text { Initial volume } \\
\text { (pre) }\end{array}$ & $\begin{array}{l}5^{\text {th }} \text { week } \\
\text { Post-tre }\end{array}$ \\
\hline Mean & 4.01 & 3.02 & 4.01 & 1.92 & 3.0 & 2.06 & 3.0 & 1.3 \\
\hline S.D. \pm & 0.14 & 0.13 & 0.14 & 0.20 & 0.14 & 0.11 & 0.14 & 0.14 \\
\hline S.E. & 0.04 & 0.04 & 0.04 & 0.06 & 0.04 & 0.11 & 0.04 & 0.04 \\
\hline t.value & \multicolumn{2}{|c|}{18.11} & \multicolumn{2}{|c|}{25.41} & \multicolumn{2}{|c|}{54.56} & \multicolumn{2}{|c|}{29.44} \\
\hline P.value & \multicolumn{2}{|c|}{0.0001} & \multicolumn{2}{|c|}{0.0001} & \multicolumn{2}{|c|}{0.0001} & \multicolumn{2}{|c|}{0.0001} \\
\hline Level of sig. & \multicolumn{2}{|c|}{ S } & \multicolumn{2}{|c|}{ S } & \multicolumn{2}{|c|}{ S } & \multicolumn{2}{|c|}{ S } \\
\hline
\end{tabular}


Table 4: The statistical analysis of the differences of wound area and volume in the control group pre\& post treatment (third and fifth weeks).

\begin{tabular}{|c|c|c|c|c|c|c|c|c|}
\hline \multirow[t]{2}{*}{ Stat. group } & \multicolumn{4}{|c|}{ Wound surface area (WSA) $\left(\mathrm{Cm}^{2}\right)$ Control group } & \multicolumn{4}{|c|}{ Wound Volume (WV) (ml) Control group } \\
\hline & $\begin{array}{c}\text { Initial Area } \\
\text { (pre) }\end{array}$ & $\begin{array}{l}3^{\text {rd }} \text { week } \\
\text { Post-tre }\end{array}$ & $\begin{array}{c}\text { Initial area } \\
\text { (pre) }\end{array}$ & $\begin{array}{c}5^{\text {th }} \text { week } \\
\text { Post-tre }\end{array}$ & $\begin{array}{l}\text { Initial Volume } \\
\text { (pre) }\end{array}$ & $\begin{array}{l}3^{\text {rd week }} \\
\text { Post-tre }\end{array}$ & $\begin{array}{l}\text { Initial volume } \\
\text { (pre) }\end{array}$ & $\begin{array}{c}5^{\text {th }} \text { week } \\
\text { Post-tre }\end{array}$ \\
\hline Mean & 4.0 & 3.64 & 4.0 & 3.23 & 3.01 & 2.61 & 3.01 & 2.33 \\
\hline S.D. \pm & 0.14 & 0.13 & 0.14 & 0.18 & 0.15 & 0.12 & 0.15 & 0.19 \\
\hline S.E. & 0.04 & 0.04 & 0.04 & 0.05 & 0.04 & 0.04 & 0.04 & 0.06 \\
\hline t.value & \multicolumn{2}{|c|}{13.50} & \multicolumn{2}{|c|}{17.17} & \multicolumn{2}{|c|}{8.94} & \multicolumn{2}{|c|}{10.25} \\
\hline P.value & \multicolumn{2}{|c|}{0.0001} & \multicolumn{2}{|c|}{0.0001} & \multicolumn{2}{|c|}{0.0001} & \multicolumn{2}{|c|}{0.0001} \\
\hline Level of sig. & \multicolumn{2}{|c|}{$S$} & \multicolumn{2}{|c|}{$S$} & \multicolumn{2}{|c|}{ S } & \multicolumn{2}{|c|}{$S$} \\
\hline
\end{tabular}

application of the treatment was $4.0 \pm 0.14 \mathrm{~cm}^{2}$, and the mean WSA values after application of standard wound care measured after the third and fifth weeks were $3.64 \pm 0.13$ and $3.23 \pm 0.18 \mathrm{~cm}^{2}$, respectively. On the other hand, the mean value and standard deviation of the WV in $\mathrm{ml}$ in this group before application of the treatment was $3.01 \pm 0.15 \mathrm{ml}$, while the mean $\mathrm{WV}$ values after application of standard wound care measured after the third and fifth weeks were 2.61 \pm 0.12 and $2.33 \pm 0.19 \mathrm{ml}$, respectively.

As observed from Table 4 there was a significant decrease in both the WSA and WV measured after the third and fifth weeks post application of standard treatment compared to the baseline values $(\mathrm{P}<0.0001)$.

Comparison and analysis of the mean values of WSA and WV for the 2 treatment groups (HBOT group and Laser group) and control group

(at baseline, and after the $3^{\text {rd }}$ and $5^{\text {th }}$ weeks) This part of the comparison of the three different groups (
HBOT, Laser, and control) was analyzed, giving following results:

Before application of the treatment:

As shown in Fig. 1 there was no significant difference in either the WSA or WV between the two treatment groups (HBOT, and Laser) and the control group $(\mathrm{P}>0.05)$.

\section{After the third week post-treatment:}

As shown in Fig. 2 during this period of measurement, there was no significant difference either in WSA or WV between the HBOT and Laser groups, but on the other hand there was a significant reduction in both WSA or WV in the HBOT and Laser groups compared with the control group.

\section{After the fifth week post-treatment:}

As shown in Fig. 3 during this period of measurement, there was a significant reduction either in WSA or WV

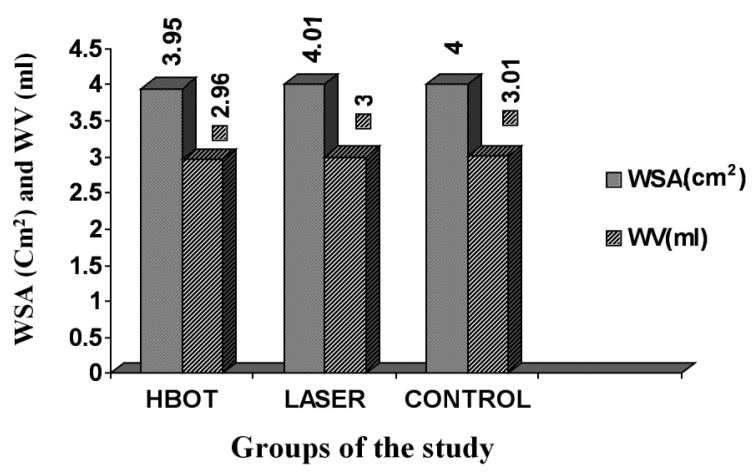

Fig. 1: Mean differences in WSA and WV pre-application of treatment in both treatment groups (HBOT and Laser) and control group.

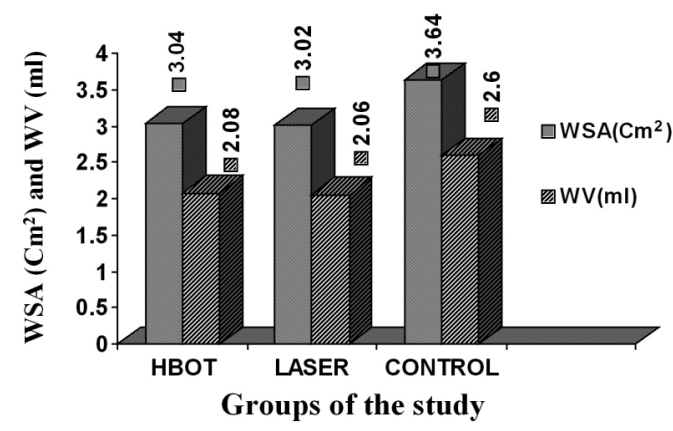

Fig. 2: Mean differences in WSA and WV post-application $\left(3^{\text {rd }}\right.$ week) of treatment in both treatment groups (HBOT and Laser) and control group. 


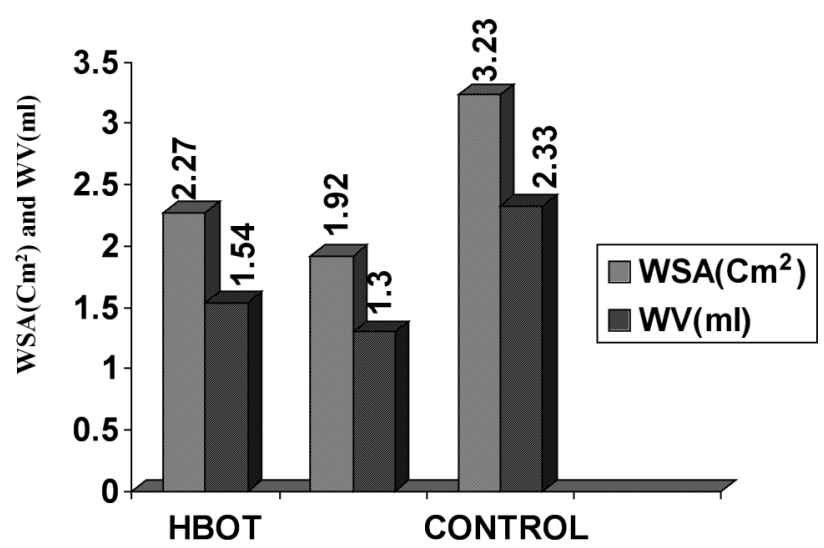

Fig. 3: Mean differences in WSA and WV post-application $\left(5^{\text {th }}\right.$ week) of treatment in both treatment groups(HBOT and Laser) and control group.

in HBOT group compared with WSA and WV in the control group as well as there was a significant reduction either in WSA or WV in Laser group compared with WSA and WV in the control group, on the other hand there was significant reduction either in WSA or in WV in Laser group compared with HBOT group.

\section{Discussion:}

This study was designed to compare the effectiveness of laser therapy and HBOT on acceleration of venous ulcer healing. No significant differences in patient or standard ulcer treatment existed between the treatment groups and the control group which would be expected to affect treatment outcome. Since all treatment groups received identical ulcer management except for the variable of the study (HBOT and laser therapy), any differences in healing between the three treatment groups could be attributed to either laser or HBOT therapy.

Numerous recent studies, focused on accelerating wound healing and considerably decreasing the time of healing, have emphasized the efficacy of HBOT in this process $^{(9)}$. The beneficial effects of laser therapy on wound healing and qualified scar formation have also been reported ${ }^{(18)}$. In this study, we aimed to compare the effects and efficacy of HBOT and laser treatment on the wound healing of chronic venous ulcers.

The result of our study revealed that laser was more effective in accelerating wound healing of venous ulcer population than the HBOT approach. This result can be explained by the ability of laser to photobiomodulate the microenvironment of the wound.

If high oxygen pressure over a long time period (several days) stimulates an abnormal angiogenesis (as demonstrated in the eyes of newborns), several studies have reported that cycling high and low oxygen pressure over a short period ( 1 or $2 \mathrm{~h}$ ) stimulates a physiological angiogenesis at the site of the ulcer. This is due, in part, to the release of collagen from fibroblasts and vascular growth factors by macrophages ${ }^{(19)}$.

Laser treatment also has been studied in wound healing. Currently, it is used in decubitis and diabetic ulcers, open wounds, venous ulcers, graft ulcers, incisions, lacerations, and burns.

The results of our study revealed that laser was very effective in reducing the wound size and volume, and this result goes hand in hand with previous studies, both in vivo and in vitro which showed that treatment with low incident levels of laser energy accelerated biochemical reactions, fibroblast activity, collagen metabolism, neovascularization, qualified scar formation, and wound formation ${ }^{(20)}$. Recommendations vary widely for the optimal energy under different conditions; the usual ranges are from 0.5 to $10 \mathrm{~J} / \mathrm{cm}^{2}$ (8) Generally, a laser with a wavelength of 600 to $984 \mathrm{~nm}$ is used in physical medicine, and a wavelength of $632.8 \mathrm{~nm}$ for the helium neon laser and $904 \mathrm{~nm}$ for the GaAs laser are used most frequently in wound healing (8). For our study, therefore, we used a GaAs laser with a wavelength of $904 \mathrm{~nm}$ and an incident energy density of $1 \mathrm{~J} / \mathrm{cm}^{2}$.

When we compared these two treatment modalities in the inflammatory phase, we found that there is no difference in the third week between HBOT and laser treatment but in the fifth week the laser treatment succeeded in decreasing the wound size and volume more than HBOT therapy. This can be explained by the ability of laser to enhance the activity of fibroblasts, amongst the other wound healing cells, more than $\operatorname{HBOT}^{(20)}$. It could be thus be concluded that the application of infrared laser therapy $1 \mathrm{~J} / \mathrm{cm}^{2}$, three times/week was more effective than the daily application of HBOT in the management of chronic venous ulcers. 


\section{References:}

1: Atabely A, Karademir S, Atabey N, Barutcu A.: “ The Effects of Helium Neon Laser on Wound Healing in Rabbits and on Human Skin Fibroblasts In Vitro.” Eur J Plast Surg 1995; 13: 99-102.

2: Augustin M, Siegel A, Heusen A : "Chronic Leg Ulcers: Cost Evaluation Of Two Treatment Strategies." J Dermatol Treat 1999; 10 (suppl 1): S21-5.

3: Baker SR, and Stacey MC.: "Epidemiology Of Chronic Leg Ulcers In Australia.” Aust New Zealand J Surg 1994; 64: 258-61.

4: Berg W., Traneroth C., Gunnarson A. \& Lossing C.: "A Method For Measuring Pressure Sores." The Lancet, 1990 ; 335:1445-1446

5: Conlan MJ, Rapley JW, Cobb CM, : "Biostimulation Of Wound Healing By Low Energy Laser Irradiation." J Clin Preiodontal 1996;23:492-496.

6: Enwemeka C.S., Parker J.C., Dowdy D.S., Harkness E.E., Sanford L.E., and Woodruff L.D. "The Efficacy Of Low Power Lasers In Tissue Repair And Pain Control: A Meta-analysis Study." Photomed Laser Surg. 2004; 22(4): 323-329.

7: Falcone PA, and Caldwell MD.: "Wound Metabolism." Clin Plast Surg. 1990;17:443-456.

8: Ghamsari SM, Taguchi K, Abe N, Acorda JA, Sato M, Yamada H.: "Evaluation Of Low Level Laser Therapy On Primary Healing Of Experimentally Induced Full Thickness Wounds In Dairy Cattle." Vet Surg. 1997;26:114-20.

9: Hammarlund C, and Sundberg T.: "Hyperbaric Oxygen Reduced Size Of Chronic Leg Ulcers: A Randomized Double-blind Study." Plast Reconstr Surg. 1994;93:829-833.

10: Hunt TK, and Pai MP.: "The Effect Of Varying Ambient Oxygen Tensions On Wound Metabolism And Collagen Synthesis." Surgery, Gynecology and Obstetrics. 1972;135:561-567.

11: Kistner RL.: "Diagnosis Of Chronic Venous Insufficiency." J Vasc Surg. 1986;3:181-184.

12: Kivisaari J, and Niinikoski J.: "Effects Of Hyperbaric Oxygenation And Prolonged Hypoxia On The Healing Of Open Wounds." Acta Chir
Scand. 1975;141:14.

13: Kitchen SS, and Partridge GJ: "A Review of Low Level Laser Therapy.” Physiotherapy 1991; 77:161168.

14: Kloth LC. and Feedar JA: "Acceleration of Wound Healing With High Voltage, Monophasic, Pulsed Current." Phys.Ther.1988;68:503-508.

15: Pai MP, and Hunt TK.: "Effect Of Varying Oxygen Tensions On Healing Of Open Wounds." Surgery, Gynecology And Obstetrics. 1972;135:756-758.

16: Pereira A.N., Eduardo CD. P., Matson E. and Marques M.M.: "Effect Of Low Power Laser Irradiation On Cell Growth And Procollagen Synthesis Of Cultured Fibroblasts." Lasers Surg Med. 2002 ; 31(4): 263-267.

17: Meyers AD: "Lasers And Wound Healing." Arch Otolaryngol Head Neck Surg 1990; 116: 1128.

18: Stadler I, Lanzafame RJ, Evans R, Narayan V, Dailey B, Buehner N, Naim JO.: "830-nm Irradiation Increases The Wound Tensile Strength In A Diabetic Murine Model." Lasers Surg Med. 2001;28:220-26.

19: Sheikh AY, Gibson JJ, Rollins MD, Hopf HW, Hussain Z, Hunt TK: "Effect Of Hyperoxia On Vascular Endothelial Growth Factor Levels In Wound Model." Arch Surg 2000;135: 1293-1297.

20: Simunovic Z, Ivankovich AD, Depolo A.: "Wound Healing Of Animal And Human Body Sport And Traffic Accident Injuries Using Low-level Laser Therapy Treatment: A Randomized Clinical Study Of Seventy-four Patients With Control Group." J Clin Laser Med Surg. 2000;18:67-73.

21: Surgrue ME, Carolan J, Leen EJ, Feeler T, Moore D, Shanik G, : "The Use of Infrared Laser Therapy in The Treatment of Venous Ulceration." Ann Vasc Surg 1990; 4: 170-181.

22: Tunér J. and Hode L."Laser Therapy-Clinical Practice and Scientific Background." Prima Books $\mathrm{AB}$, Grangesberg, Sweden. Chapter 1. Some basic laser physics. pp. 12, 21, 22.

23: Young SR, Dyson M, "The Effect of Light On Tissue Repair.” Acupunct Med 1993; 11: 17-18. 